\title{
Establishment of an Environmental Control Technology Laboratory With a Circulating Fluidized-Bed Combustion System
}

\author{
Quarterly Technical Progress Report
}

April 1 - June 30, 2004

Wei-Ping Pan, Kunlei Liu, and John T. Riley

July 30, 2004

Cooperative Agreement No. DE-FC26-03NT41840

Institute for Combustion Science and Environmental Technology

Western Kentucky University

1 Big Red Way

Bowling Green, KY 42101 


\section{DISCLAIMER}

This report was prepared as an account of work sponsored by an agency of the United States Government. Neither the United States Government nor any agency thereof, nor any of their employees, makes any warranty, express or implied, or assumes any legal liability or responsibility for the accuracy, completeness, or usefulness of any information, apparatus, product, or process disclosed, or represents that its use would not infringe privately owned rights. Reference herein to any specific commercial product, process, or service by trade name, trademark, manufacturer, or otherwise does not necessarily constitute or imply its endorsement, recommendation, or favoring by the United States Government or any agency thereof. The views and opinions of authors expressed herein do not necessarily state or reflect those of the United States Government or any agency thereof. 


\begin{abstract}
This report presents the progress made on the project "Establishment of an Environmental Control Technology Laboratory (ECTL) with a Circulating Fluidized-Bed Combustion (CFBC) System" during the quarter April 1 - June 30, 2004. The following tasks have been completed. First, the final specifications for the renovation of the new Combustion Laboratory and the construction of the CFB Combustor Building have been delivered to the architect, and invitations for construction bids for the two tasks have been released. Second, the component parts of the CFBC system have been designed after the design work for assembly parts of the CFBC system was completed. Third, the literature pertaining to Polychlorinated Dibenzo-p-Dioxins (PCDD) and Polychlorinated Dibenzofurans (PCDF) released during the incineration of solid waste, including municipal solid waste (MSW) and refuse-derived fuel (RDF) have been reviewed, and an experimental plan for fundamental research of MSW incineration on a simulated fluidized-bed combustion (FBC) facility has been prepared. Finally, the proposed work for the next quarter has been outlined in this report.
\end{abstract}




\section{TABLE OF CONTENTS}

DISCLAIMER $\ldots \ldots \ldots \ldots \ldots \ldots \ldots \ldots$

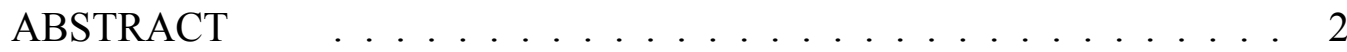

TABLE OF CONTENTS . . . . . . . . . . . . . . 3

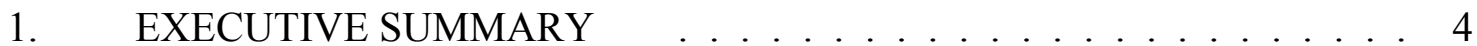

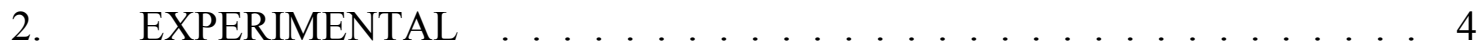

2.1 Renovation of Combustion Laboratory and Construction of CFB 4

Combustor Building

2.2 Arrangement of Measurement and Sampling Ports in CFBC System 5

2.3 Design and Drawing of Component Parts for CFBC Facility 6

2.4 Modifications to Laboratory-Scale Simulated FBC Facility 6

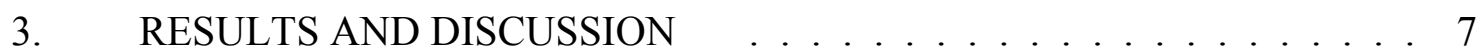

3.1. Renovation of Combustion Laboratory and Construction of CFB 7

Combustor Building

3.2. Literature Review of MSW and RDF Incineration 8

3.3. Experimental Plan for MSW and RDF incineration on a Simulated FBC 9

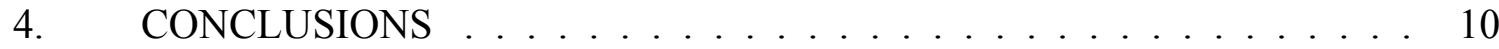

5. FUTURE WORK AND UPDATED SCHEDULE . . . . . . . . . . . 11

5.1 Future Work 11

5.2 Updated Schedule 12

ACRONYMS AND ABBREVIATIONS . . . . . . . . . 13

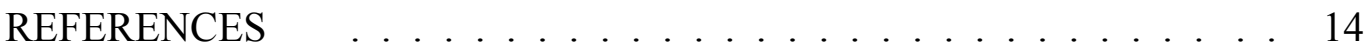




\section{EXECUTIVE SUMMARY}

In this quarter (April 1 - June 30, 2004), work on the project was concentrated on renovating space for a new combustion laboratory, designing a multi-functional CFBC Facility, and constructing a CFB Combustor Building. The purpose of this report is to summarize the progress made in the third quarter of this project. Based on the work completed during the previous quarter (January 1 - March 31, 2004) of the project, the following progress has been made. First, the final specifications for the renovation of the new Combustion Laboratory and the construction of the CFB Combustor Building have been delivered to the architect, and invitations for construction bids for these two tasks have been released. Second, the component parts of the CFBC system have been designed after the design work for assembly parts of the CFBC system were completed. Third, the most recent literature pertaining to MSW incineration have been searched and collected. Fourth, some modifications to the laboratory-scale simulated FBC facility have been completed in order to permit the burning of MSW in this facility. An experimental plan for the co-combustion of MSW and high sulfur coal in this facility has also been developed. Finally, the outline of work needed to be conducted during the next quarter is briefly introduced, and the reasons for delays of some tasks are also explained.

\section{EXPERIMENTAL}

\subsection{Renovation of Space for the Combustion Laboratory and Construction of the CFB}

\section{Combustor Building}

In this quarter, the renovation of the space for the new Combustion Laboratory and the construction of the CFBC Facility building have progressed significantly. The following accomplishments have been achieved through close cooperation with the architects:

- Established the final floor space size, arrangement, laboratory furnishings, and utility requirements, including emergency power and cooling water provision.

- Established the final size and design of cooling water supply, both standard operating mode and electric utility interruption (EUI) mode.

- Established the final size and design of utility services, such as electric power, including emergency generator/transfer switch capacity, definition of supported loads, 
and a newly added $90 \mathrm{KW}$ electric preheater for the materials in the combustor bed. Also finalized were the size of the water supply, including emergency cooling water used in case of EUI and emergency cooling water discharge facility. Natural gas requirements for laboratory applications and quality and quantity of compressed air were also established.

- Established the layout of the fuel and flue gas analysis facility.

- Identified the final size and design of electric service components.

- Established the layout of control room facility, including emergency lighting and power provision.

\subsection{Arrangement of Measurement and Sampling Ports in CFBC System}

Based on the strategies for measurement and the sampling system proposed in the first quarter of the project, the details for measurement and sampling ports in the CFBC system have been arranged and designed. The ports include the following:

- Pressure sensor ports. Pressure sensor ports are arranged along the bed height and the solid circulation loop. These pressure sensors monitor the pressure inside the CFBC system. Furthermore, these sensors provide information to operators so that adjustments may be made to the CFBC system.

- Thermocouple ports. Thermocouple ports are used to detect the distribution of bed temperatures inside the bed. Using information from these thermocouples, operators can control the temperature of the CFBC system.

- Peeling windows. These windows are deployed on the coal feeding standpipe and the solid circulation loop. They are used to monitor the solids flow inside the pipes in order to quickly locate solids blockages.

- Gas and solids sampling ports. In experiments on the CFBC system, gas and solids samples need to be captured to study the combustion behavior and pollutant emission characteristics for different fuels.

- Solids flow rate measurement device. The solids circulating ratio is an important parameter that requires monitoring. An on-line solids flow rate measurement device installed in the solids circulation loop monitors the solids flow rate in the CFBC system. 
- Gas flowmeter. Primary and secondary air are controlled and measured by gas flowmeters, respectively.

- Water flowmeter. Cooling water supplied for different cooling sections is controlled and regulated by corresponding water flowmeters.

\subsection{Design and Drawing of Fabrication Diagrams for Component Parts of the CFBC Facility}

Based on the final concept design of the CFBC Facility and the drawings of assembly parts, detailed component parts of the CFBC facility have been designed and drawn individually. The component parts include pipe sections, flanges, gaskets, tubing sections, etc. This work also included choosing standard parts in order to reduce the processing work. It is time-consuming to prepare these drawing for component parts. A significant amount of time was spent on these component part drawings during this quarter. However, these drawings are very important and are essential to the successful fabrication of these parts by the manufacturer in the next phase. Since the number of these component parts is large, the list of these component parts is not shown here, however, these drawings are available on request.

\subsection{Modifications to the Laboratory-Scale Simulated FBC Facility}

Although the laboratory-scale simulated FBC system was set up in the first quarter of the project, the mini-solids screw feeder was found to be not suitable for feeding the coarse coal particles and solid waste materials into the combustion chamber. In fact, the mini-screw feeder can only deliver pulverized coal, so a new screw feeder was needed. Due to its small flowrate, a special order requiring a long-lead time was placed with the manufacturer for the design and fabrication of this special mini screw feeder. In order to burn MSW and RDF, a 3.0" pipe (3.5" O.D. and 3.0" I.D.) was used to replace the previous laboratory-scale FBC system's 1.5" pipe (1.9" O.D. and 1.6" I.D.). Therefore, the cross-section area of the fluidized bed increased by $250 \%$. This modification allowed the FBC facility to burn MSW and RDF. A new split electric furnace with two sections was ordered to satisfy the heating requirement for the studies contemplated under this plan. This allowed the fuel feeding point to be changed from the top of the bed to underneath the surface of the bed. These significant changes delayed the experiments on the laboratory-scale simulated FBC system. 


\section{RESULTS AND DISCUSSION}

\subsection{Renovation of the Space for the New Combustion Laboratory and Construction of the}

\section{CFB Combustor Building}

The final specifications for the renovation of the space for the new Combustion Laboratory and the construction of the CFB Combustor Building have been delivered to the architect. Invitations for construction bids for renovation of Combustion Laboratory and the construction of the CFB Combustor Building have been advertised. The bid invitation period will close on, and the evaluation of bid proposals is expected to begin on August 15, 2004. Construction contracts for both tasks will be awarded during the next quarter. Renovation of the space for the new Combustion Laboratory and the construction of the CFB Combustor Building should commence in September of this year. Originally, the award of the construction contract was expected to be on January 5, 2004.

Explanations of delays are given in the following:

$>$ Although the "final design and specifications" were delivered to the architects on March 26, 2004, the architectural firm developed estimates of bid costs that exceeded the budgeted funds allocated for the construction and renovation components of the project. Bid cost estimates have been driven up this year by a locally strong construction industry and substantial increases in steel costs, which the CFB Combustor Building design requires.

$>$ As a result, a new round of cost containment/reduction strategies were developed during this quarter to meet the essential needs for this project.

$>$ The combustor bed preheater design was changed from natural gas-fired to electricpowered. Although a bed material preheater fired with natural gas would heat the bed material faster and with a lower operational cost per session, the capital costs were estimated to be much greater due to its unique design and fabrication considerations. Further, a natural gas-fired bed material preheater must have much more elaborate safety controls and poses a greater liability burden. Following this line of reasoning, the architects were instructed to provide bid estimates based upon employing electric- 
powered bed preheating equipment. The full project specification supporting this option was communicated to the architects on June 30, 2004 and is presently being developed, including revised estimated bid costs.

$>$ Items of equipment were changed in order to operate on a power supply supported, in case of an electric utility interruption (EUI), by an engine powered generator set and automatic transfer switch. A detailed assessment of all electric loads planned by the architects to be supported by emergency power revealed a number of changes that would substantially reduce the size and cost of the generator set and its associated automatic transfer switch. Further, the architects have confirmed that the generator set cost would be reduced by nearly $50 \%$ by specifying that it be fueled by diesel rather than by natural gas. The architects were also provided with a series of revised specifications and associated drawings, changes that will significantly reduce generator, automatic transfer switch, and other electrical component costs.

\subsection{Literature Review of MSW and RDF Incineration}

During the incineration of solid waste, including MSW and RDF, many organic products resulting from incomplete combustion are generated, including chlorinated species such as polychlorinated biphenyls (PCB), polychlorinated dibenzo-p-dioxins (PCDD), and polychlorinated dibenzofurans (PCDF). Since these organic compounds are of environmental concern, a lot of research has been conducted to understand their formation. There are two temperature windows in which they can form: the first route is a "homogeneous" reaction that takes place between a temperature of $500^{\circ} \mathrm{C}$ and $800^{\circ} \mathrm{C}$; and the second route is a "heterogeneous" reaction between a temperature of $200^{\circ} \mathrm{C}$ and $400^{\circ} \mathrm{C}$. Homogeneous reactions are considered the result of the pyrolytic rearrangement of chlorinated precursors, such as chlorophenols and chlorobenzenes in the gas phase. So far, the homogeneous reaction mechanism has been studied as extensively as the heterogeneous mechanism. Heterogeneous formation is viewed as a catalyzed reaction, which takes place on the ash or soot particles in the combustion system. There are conflicting views regarding the relative amounts of PCDD and PCDF formed from precursors such as chlorophenols in comparison with the de novo process during commercial operations. The oxidation and chlorination of any unburned carbon in particulates are involved in the de novo reactions. The reaction routes for de novo PCDD and 
PCDF are based on pre-existing 3-ring carbon skeletons; single-ring chlorinated precursors are not intermediates. Oxidation is considered as the driving force to the formation reaction, and the carbon burn-off is viewed as a factor to the reaction rate. Dechlorination and decomposition are carried out at elevated temperatures. The reaction seems to take place on the external surface of the particles, but is determined by the carbon and chlorine contents. In the process of de novo reactions, chlorine is an active agent, either as chloride in the solid phase or as atomic chlorine in the gas phase. Solid-phase chlorine always makes a contribution, while gas-phase chlorine is only active at higher concentrations when the solid phase is depleted. An excess of chlorine appears to inhibit de novo reactions. Different mechanisms are postulated for PCDD and PCDF formation. Single- and multi-ring species chlorinate differently, along different pathways. The single-ring compounds formed are comparatively loosely held, while the multi-ring species tend to be strongly held. Much of the PCDD/F formed is retained on the solid surface and is unable to equilibrate with the gas phase under flue gas atmosphere conditions. De novo catalysis is due mainly to copper, although iron and other metals are active at lower rates. Copper catalyzes the oxidation of carbon, as well as the chlorination and dechlorination of organic products. In its two oxidation states it also acts as a "shuttle" for chlorine between gas and solid phases. The catalytic effect can be poisoned by sulfur or nitrogen compounds, such as sulfur dioxide or urea. All the formation models proposed to date, both for the homo-and heterogeneous routes, are inadequate, no doubt as a result of the complexity of the processes. The homogeneous route needs more fundamental research, and with regard to the de novo route, more attention needs to paid to the composition and nature of the ash surface, including particle size and carbon/catalyst disposition.

\subsection{Experimental Plan for MSW and RDF Incineration in a Simulated FBC}

The purpose of the experiments to be conducted in the modified laboratory-scale simulated FBC facility are to study mechanisms for the formation of pollutants during the cocombustion of MSW, biomass, and RDF blends with high sulfur coal.

- Fuels to be used in these experiments are Kentucky high sulfur coal that contains about $4 \%$ sulfur by weight. Solid waste materials are RDF that is made from paper pellets and simulated MSW that is made of plastic scraps. 
- Operation parameters to be studied include bed temperature, excess air rates, solid waste/coal ratios, types of coal and limestone, Calcium to Sulfur $(\mathrm{Ca} / \mathrm{S})$ and Calcium to Chlorine $(\mathrm{Ca} / \mathrm{Cl})$ molar ratios, and catalysis. The effects of these parameters on PCDD and PCDF formation are to be investigated.

- Measurement methods to be used in these experiments include a 1312 Potoacoustic Multi-Gas Monitor which detects Ammonia $\left(\mathrm{NH}_{3}\right)$, Hydrochloric Acid ( $\left.\mathrm{HCl}\right)$, Nitrous Oxide $\left(\mathrm{N}_{2} \mathrm{O}\right)$, Sulfur Dioxide $\left(\mathrm{SO}_{2}\right)$, and Carbon Dioxide $\left(\mathrm{CO}_{2}\right)$, a Combustion Gas Analyzer IMR 700 which monitors Oxygen $\left(\mathrm{O}_{2}\right)$, Carbon Monoxide (CO), Nitric Oxide (NO), Nitrogen Dioxide $\left(\mathrm{NO}_{2}\right), \mathrm{SO}_{2}$, and $\mathrm{CO}_{2}$, a LECO GC/TOF-MS and an LC/MS system which measure the organic residues.

To investigate the exact details of the mechanism for the formation of chlorides and polychlorinated organics, the following kinetic studies will be conducted in these experiments:

- Conditions for the oxidation of $\mathrm{HCl}$ to Chlorine $\left(\mathrm{Cl}_{2}\right)$ (Deacon reaction) in flue gas atmosphere.

- Reaction conditions for Copper Oxide $(\mathrm{CuO}), \mathrm{O}_{2}$, and $\mathrm{SO}_{2}$ to form Copper Sulfate $\left(\mathrm{CuSO}_{4}\right)$.

- Conditions for the formation of polychlorinated organics.

\section{CONCLUSIONS}

In the third quarter of the project, the following activities have been completed:

- After identifying the size and design completely, the final specifications for the Combustion Laboratory and the CFB Combustor Building have been delivered to the architect. Invitations for construction bids for the renovation of the space for the new Combustion Laboratory and the construction of the CFB Combustor Building have been issued.

- To control and adjust this CFBC Facility efficiently, the measurement and sampling ports in the CFBC system have been arranged and designed in accordance with the principle proposed in the first quarter of the project. This work will be helpful in the future study of combustion behavior and pollutant emission characteristics. 
- Based on the assembly parts designed for the CFBC Facility last quarter, all component parts have been designed and fabrication diagrams have been drawn. This work has laid a solid foundation for awarding the fabrication contract to manufacture the component parts of CFBC system in the next stage.

- To fit the requirements for the co-combustion of the solid waste (including MSW and RDF) with high sulfur coal, the laboratory-scale simulated FBC facility has been modified. Based on the literature review about PCDD and PCDF formation during MSW incineration, an experimental plan for conducting fundamental research with this modified simulated FBC Facility has been proposed.

\section{FUTURE WORK AND UPDATED SCHEDULE}

\subsection{Future Work}

In the next quarter, efforts will be focused on the following activities:

- The bid invitation will be closed and bid proposals will be evaluated.

- Assist and consult with architects and engineers on the selection of contractors for the renovation of space for the new Combustion Laboratory and construction of the CFB Combustor Building.

- After construction contracts for both areas have been awarded, renovation of the space for the new Combustion Laboratory and construction of the CFB Combustor Building will start.

- Organize the corresponding technical personnel to review the drawings of all component parts of the CFBC Facility.

- Award the contracts for fabricating all component parts for the CFBC Facility. Work together with suppliers and fabricators to manufacture these component parts.

- Conduct experiments on the modified laboratory-scale simulated FBC Facility. The following experiments will be carried out on this laboratory-scale simulated FBC facility in the next quarter: 
- Investigate conditions for the oxidation of $\mathrm{HCl}$ to chlorine $\left(\mathrm{Cl}_{2}\right)$ (Deacon reaction) in a flue gas atmosphere. The experimental data will be analyzed based on the chemical reaction kinetics.

* Study reaction conditions for copper oxide $(\mathrm{CuO}), \mathrm{O}_{2}$, and $\mathrm{SO}_{2}$ to form copper sulfate $\left(\mathrm{CuSO}_{4}\right)$.

\subsection{Updated Schedule}

So far total four tasks are being conducted in this fiscal year. Based on the current progresses made on the project, the updated schedule for these tasks is shown in Table 1.

Table 1. The updated schedule for current conducted tasks

\begin{tabular}{|l|c|}
\hline \multicolumn{1}{|c|}{ Task } & Updated Schedule \\
\hline $\begin{array}{l}\text { Close bid invitation and begin evaluation of bid proposals for } \\
\text { renovation of the space for the new Combustion Laboratory } \\
\text { and construction of the CFB Combustor Building }\end{array}$ & August 15,2004 \\
\hline Award construction contracts for both tasks & August 31, 2004 \\
\hline Commence renovation of Combustion Laboratory & September 15, 2004 \\
\hline Commence construction of new CFB Combustor Building & September 29, 2004 \\
\hline $\begin{array}{l}\text { Start to review all drawings of the bench-scale 0.6MW } \\
\text { CFBC Facility. }\end{array}$ & September 20, 2004 \\
\hline $\begin{array}{l}\text { Finish modifications to the laboratory-scale simulated FBC } \\
\text { Facility }\end{array}$ & August 30, 2004 \\
\hline $\begin{array}{l}\text { Start to do the experiments for fundamental research on the } \\
\text { laboratory-scale FBC Facility }\end{array}$ & September 5, 2004 \\
\hline
\end{tabular}


ACRONYMS AND ABBREVIATIONS

$\mathrm{Ca} / \mathrm{Cl}$ Calcium to Chlorine Molar Ratio

$\mathrm{Ca} / \mathrm{S} \quad$ Calcium to Sulfur Molar Ratio

CFB Circulating Fluidized-Bed

CFBC Circulating Fluidized-Bed Combustion

$\mathrm{Cl}_{2} \quad$ Chlorine

CO Carbon Monoxide

$\mathrm{CO}_{2} \quad$ Carbon Dioxide

$\mathrm{CuO} \quad$ Copper Oxide

$\mathrm{CuSO}_{4} \quad$ Copper Sulfate

DOE U.S. Department of Energy

ECTL Environmental Control Technology Laboratory

EUI Electric Utility Interruption

FBC Fluidized-Bed Combustion

$\mathrm{HCl} \quad$ Hydrochloric Acid

I.D. Inside Diameter

KW Kilowatt

MSW Municipal Solid Waste

$\mathrm{NH}_{3} \quad$ Ammonia

NO Nitric Oxide

$\mathrm{NO}_{2} \quad$ Nitrogen Dioxide

$\mathrm{NO}_{\mathrm{x}} \quad$ Nitrogen Oxides

$\mathrm{N}_{2} \mathrm{O} \quad$ Nitrous Oxide

$\mathrm{O}_{2} \quad$ Oxygen

O.D. Outside Diameter

PCB Polychlorinated Biphenyls

PCDD Polychlorinated Dibenzo- $p$-Dioxins

PCDF Polychlorinated Dibenzofurans

RDF Refuse-Derived Fuel 
$\mathrm{SO}_{2} \quad$ Sulfur Dioxide

$\mathrm{SO}_{\mathrm{x}} \quad$ Sulfur Oxides

\section{REFERENCES}

1. B. R. Stanmore, The Formation of Dioxins in Combustion Systems, Combustion and Flame, 2004, 136, 398.

2. M. Goemans, P. Clarysse, J. Joannes, P. De Clercq, S. Lenaerts, K. Matthys, and K. Boels, Catalytic $\mathrm{NO}_{\mathrm{x}}$ Reduction with Simultaneous Dioxin and Furan Oxidation, Chemosphere, 2004, 54, 1357.

3. K. Tagashira, I. Torii, K. Myouyou, K. Takeda, T. Mizuko, and Y. Tokushita, "Combustion Characteristics and Dioxin Behavior of Waste Fired CFB," Chemical Engineering Science, 1999, 54, 5599.

4. K. Liu, W.-P. Pan, and J.T. Riley, A Study of Chlorine Behavior in a Simulated Fluidized Bed Combustion System, Fuel, 2000, 79, 1115.

5. G. McKay, Dioxin Characterization, Formation and Minimization during Municipal Solid Waste (MSW) Incineration: Review, Chemical Engineering Journal, 2002, 86, 343.

6. Y. Xie, The Effect of $\mathrm{SO}_{2}$ on the Formation of $\mathrm{Cl}_{2}$ during Co-firing Municipal Solid Waste with Coal, Master Thesis, Western Kentucky University, 1998.

7. P. Basu and S. A. Fraser, Circulating Fluidized Bed Boilers Design and Operations, Buttersworth-Heinemann, Oxford, the United Kingdom, 1991.

8. E. A. Avallone and T. Baumeister III, Marks' Standard Handbook for Mechanical Engineers, (10 ${ }^{\text {th }}$ edition), McGraw-Hill, New York, 1996.

9. R. H. Perry and D. W. Green, Perry's Chemical Engineers' Handbook, (Platinum Edition), McGraw-Hill, New York, 1999. 